P-ISSN 2580 - 7781

E-ISSN 2615 - 3238

\title{
PENENTUAN STATUS MUTU AIR DENGAN METODE INDEKS PENCEMARAN DI PERAIRAN PASIR PUTIH SITUBONDO
}

\section{DETERMINING OF WATER QUALITY STATUS USING POLLUTION INDEX METHOD AT PASIR PUTIH SITUBONDO}

\author{
Anita Diah Pahlewi ${ }^{1)}$, Herdiana Rahayu ${ }^{2)}$ \\ ${ }^{1}$ Prodi Teknik Kelautan, Fakultas Pertanian, Universitas Abdurachman Saleh Situbondo \\ ${ }^{2}$ Dinas Lingkungan Hidup dan Perhubungan Kabupaten Bondowoso \\ Email : ${ }^{1}$ anitadiah123@gmail.com
}

\begin{abstract}
ABSTRAK
Kawasan pesisir Pasir Putih merupakan salah satu wisata bahari andalan Kabupaten Situbondo. Pengetahuan mengenai kualitas perairan Pasir Putih sangat penting untuk dilakukan.Penelitian ini bertujuan untuk mengetahui dan menentukan tingkat kualitas air sebagai gambaran kualitas perairan Pasir Putih. Pengambilan data kualitas air menggunakan metode insitu yaitu pengambilan data secara langsung di lapangan dan pengambilan data melalui pengujian di laboratorium. Analisa data hasil pengukuran parameter kualitas air yang didapatkan kemudian dihitung dengan metode Indeks Pencemaran. Perbandingan data hasil pengukuran parameter kekeruhan dan TSS dengan baku mutu untuk wisata bahari menunjukkan bahwa kekeruhan dan TSS nilainya tidak melebihi nilai standar baku mutu yang ditetapkan.Nilai pengujian $\mathrm{pH}, \mathrm{DO}, \mathrm{BOD}$, dan fosfat berada pada rentang nilai yang diijinkan oleh standar baku mutu, kecuali nitrat yang melebihi nilai ambang batas baku mutu yang telah ditetapkan. Nilai Indeks Pencemaran Stasiun 1 sebesar 8.815; Stasiun 2 sebesar 7.943; Stasiun 3 sebesar 8.932; Stasiun 4 sebesar 8.656; Stasiun 5 sebesar 9.432; Stasiun 6 sebesar 9.178. Berdasarkan hubungan tingkat ketercemaran dengan kriteria Indeks Pencemaran dapat diketahui bahwa status mutu air Stasiun 1 hingga Stasiun 6 tercemar sedang karena 5,0 $\leq \mathrm{PIj} \leq 10$.
\end{abstract}

Kata Kunci: Status Mutu Air; Indeks Pencemaran; Perairan Pasir Putih

\begin{abstract}
Pasir Putih coastal area known as one of the mainstays of marine tourism at Situbondo Regency. It is important to know about the information of Pasir Putih water quality. The aim of this research is to know and determine the level of water quality as a description of Pasir Putih water quality. Retrieval of water quality data using the in situ method, taking data directly in the field, and collecting data through testing in the laboratory. Analysis of the data obtained from the measurement of water quality parameters is then calculated by the Pollution Index method. The comparison of turbidity and TSS parameters with the quality standards for marine tourism shows that the turbidity and TSS values do not exceed the established quality standard values. The values for $\mathrm{pH}, \mathrm{DO}$, $B O D$, and phosphate are in the range of values permitted by the quality standard, except for the nitrate which exceeds the water quality standard.. The Pollution Index Value of Station 1 is 8,815; Station 2 is 7,943; Station 3 is 8,932; Station 4 amounting to 8,656; Station 5 is 9,432; Station 6 is 9,178. Based on the relationship between the level of pollution and the criteria for the Pollution Index, it can be seen that the water quality status of Station 1 to Station 6 is moderately polluted because $5.0 \leq P I j \leq 10$.

Keywords: Water Quality Status; Pollutant Index; Pasir Putih Water
\end{abstract}


P-ISSN 2580 - 7781

E-ISSN 2615 - 3238

\section{PENDAHULUAN}

Air merupakan komponen terbesar yang menyusun permukaan bumi dan termasuk sumber daya alam penting yang dibutuhkan oleh semua makhluk hidup. Pemanfaatan dan pengelolaan air untuk kehidupan harus dilakukan secara bijaksana terkait keberlangsungannya untuk masa depan. Effendi (2003:12) menyebutkan bahwa pemantauan dan interpretasi data kualitas air menjadi langkah konkret untuk pengelolaan sumber daya air yang sangat penting agar air dapat dimanfaatkan secara berkelanjutan dengan tingkat mutu yang diinginkan.

Kualitas air menurut Peraturan Pemerintah RI No. 20 tahun 1990 adalah sifat air dan kandungan makhluk hidup, zat, energi, atau komponen lain didalam air. Kualitas air dinyatakan dengan beberapa parameter, yaitu parameter fisika (suhu, kekeruhan, padatan terlarut, dan sebagainya), parameter kimia ( $\mathrm{pH}$, oksigen terlarut, BOD, kadar logam, dan sebagainya), dan parameter biologi (keberadaan plankton, bakteri, dan sebagainya). Menurut Hariyadi dan Efendi (2016:8), kualitas air adalah komponen perairan paling dinamis yang dapat berubah karena pengaruh antropogenik, dinamika laut, musim, dan cuaca.

Penelitian mengenai kualitas air telah dilakukan oleh banyak peneliti, antara lain, Mishra et al (2015:959) melakukan evaluasi kualitas air sungai di kota Chennai dan menemukan bahwa kelebihan fosfor dan nitrogen menyebabkan eutrofikasi yang menyebabkan blooming alga. Studi status mutu air yang dilakukan Matahelumual (2007:116) menyebutkan bahwa air di Kecamatan Bantar Gebang tahun 2002 tidak memenuhi persyaratan air minum dan berdasarkan penilaian sistem STORET disimpulkan bahwa mutu air tersebut buruk. Penelitian Hamuna et al (2018:35) mengenai kualitas air laut di perairan Distrik Depapre, Jayapura, menunjukkan bahwa perairan Distrik Depapre berada dalam kategori tercemar ringan hingga tercemar sedang. Dengan mengetahui gambaran kualitas perairan pesisir dan laut diharapkan dapat mengambil langkah nyata untuk memulihkan kondisi perairan yang berkategori buruk dan dapat mempertahankan bagi perairan berkategori baik.

Berdasarkan Sukandar et al (2016:111), Situbondo memiliki garis pantai sepanjang $131.575 \mathrm{~km}$ dan wisata bahari menjadi andalan untuk pariwisatanya. 
P-ISSN 2580 - 7781

E-ISSN 2615 - 3238

Salah satu contohnya adalah kawasan pesisir Pasir Putih Situbondo. Obyek wisata yang tersedia di Pasir Putih menjadi penunjang perekonomian bagi masyarakat sekitar. Selain itu, Pemerintah Kabupaten Situbondo berupaya untuk melindungi kelestarian terumbu karang, sumberdaya ikan serta ekosistemnya, dan mengelola ekosistem perairan melalui Peraturan Bupati Situbondo Nomor 19 Tahun 2012 tentang Pencadangan Kawasan Terumbu Karang Pasir Putih Sebagai Kawasan Konservasi Perairan Daerah Kabupaten Situbondo. Perubahan tata guna lahan dan pembangunan infrastruktur yang mengakibatkan sedimentasi dan atau erosi, terlepasnya zat pencemar dari limbah rumah tangga yang tidak dikelola dengan baik, dan masuknya bahan kimia beracun ke perairan pesisir dan laut merupakan dampak negatif yang bisa menyebabkan penurunan kualitas air di sekitar perairan pesisir dan laut sertadapat berakibat pada perekonomian di daerah tersebut. Oleh karena itu, mengetahui kualitas perairan Pasir Putih menjadi sangat penting untuk dilakukan.

Penelitian sebelumnya mengenai kualitas air di Keramba Jaring Apung Pasir Putih Situbondo dilakukan oleh P Anrosana (2017:77) menunjukkan bahwa kualitas air di kawasan keramba jaring apung secara umum masih sesuai baku mutu air laut, tetapi data hasil penelitian yaitu salinitas dan nitrat melebihi baku mutu yang ditetapkan Kepmen LH No. 51 Tahun 2004. Data parameter lingkungan dalam penelitian Subagio dan Aunurohim (2013:E-161)menunjukkan parameter kecerahan dan salinitas tidak ada yang melebihi batas rentang hidup untuk spons laut. Penelitian yang khusus membahas kualitas air dari segi parameter fisika dan kimia menggunakan metode Indeks Pencemaran di perairan Pasir Putih Situbondo belum dilakukan. Penelitian ini bertujuan untuk mengetahui dan menentukan tingkat kualitas air untuk mendapatkan gambaran kualitas perairan Pasir Putih Situbondo. Penelitian ini diharapkan menjadi bahan monitoring kualitas perairan dan dasar untuk penelitian selanjutnya mengenai status kualitas perairan untuk dijadikan referensi penentuan status mutu laut Kabupaten Situbondo. 
P-ISSN $2580-7781$

E-ISSN 2615 - 3238

\section{METODE PENELITIAN}

Daerah penelitian ini adalah perairan Pasir Putih Kecamatan Bungatan Kabupaten Situbondo, Jawa Timur. Letak astronomis Desa Pasir Putih adalah 7.691019 LS- 113.829153 BT dan memilikipanjang garis pantai $1-5 \mathrm{~km}^{2}$. Penelitian dilaksanakan pada musim kemarau dan kondisi surut. Pengambilan data kualitas air pada perairan Pasir Putih menggunakan metode in situyaitu pengambilan data secara langsung di lapangan dan pengambilan data melalui pengujian di laboratorium.

Pengambilan sampel air laut yang memerlukan analisis laboratorium dilakukan dengan memasukkan sampel air laut ke dalam botol dan disimpan dalam coolbox untuk dianalisis di Laboratorium. Tabel 1 menyajikan jenis parameter kualitas air yang diuji dalam penelitian ini, tipe analisis, dan metode analisis yang digunakan.

Tabel 1. Parameter, tipe analisis dan spesifikasi alat penelitian

\begin{tabular}{ccc}
\hline Parameter & Tipe Analisis & Spesifikasi Alat/Metode Analisis \\
\hline Koordinat lokasi & Insitu & GPS \\
\hline Parameter Fisika & & Turbidimetrik \\
\hline Kekeruhan & Laboratorium & Kolorimetrik \\
\hline TSS & Laboratorium & \\
\hline Parameter Kimia & & IKM/7.2.15/BPBAPS \\
\hline pH & Laboratorium & Titrimetrik \\
\hline DO & Laboratorium & BOD meter \\
\hline BOD & Laboratorium & Kolorimetrik \\
\hline Nitrat & Laboratorium & Spektrofotometrik \\
\hline Fosfat & Laboratorium &
\end{tabular}

Analisa data hasil pengukuran insitu dan hasil analisis laboratorium parameter kualitas air yang didapatkan kemudian dilakukan perhitungan untuk menentukan status mutu air dengan metode Indeks Pencemaran sebagai berikut: 
P-ISSN $2580-7781$

E-ISSN 2615 - 3238

$P_{i}=\sqrt{\frac{\left(C_{i} / L_{i i}\right)_{M}^{2}+\left(C_{i} / L_{i j}\right)_{R}^{2}}{2}}$

Dimana:

Lij : Konsentrasi parameter kualitas air idalam baku mutu peruntukan air $\mathrm{j}$

$\mathrm{Ci} \quad$ : Konsentrasi parameter kualitas air i

PIj : Indeks Pencemaran bagi peruntukan $\mathrm{j}$

(Ci/Lij)M : Nilai Ci/Lij Maksimum

(Ci/Lij)R : Nilai Ci/Lij Rerata

Hubungan tingkat ketercemaran dengan kriteria indeks pencemaran yaitu:

1. $0 \leq \operatorname{PIj} \leq 1,0 \quad$ : memenuhi baku mutu (kondisi baik)

2. $1,0 \leq \mathrm{PIj} \leq 5,0 \quad$ : tercemar ringan

3. $5,0 \leq \mathrm{PIj} \leq 10 \quad$ : tercemar sedang

4. $\mathrm{PIj}>10 \quad$ : tercemar berat

\section{HASIL PENELITIAN DAN PEMBAHASAN}

Lokasi untuk mendapatkan contoh air yang akan diuji yaitu perairan Pasir Putih, Kabupaten Situbondo, dan dilakukan pada 6 stasiun pengambilan sampel.

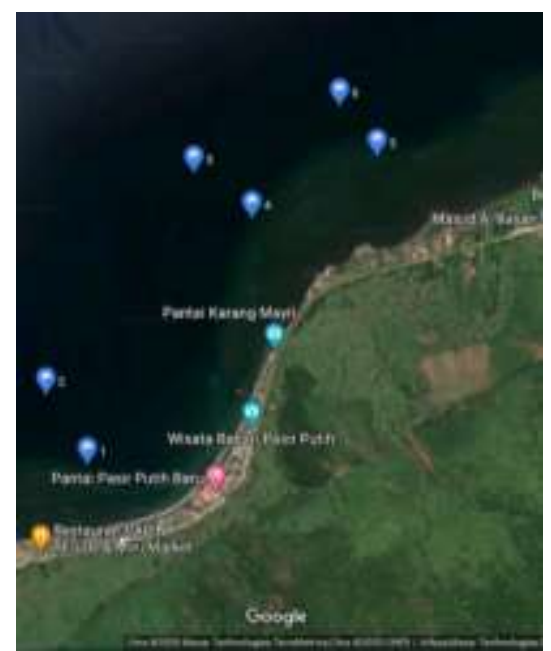

Gambar 1. Stasiun pengambilan sampel air di perairan Pasir Putih Situbondo (Google Earth, 2020)

Koordinat stasiun-stasiun pengambilan sampel air yaitu sebagai berikut:

Stasiun $1=7^{\circ} 41^{\prime} 39.4188^{\prime \prime S}$ dan 11349'25.6368"E

Stasiun $2=7^{\circ} 41^{\prime} 31.686 " \mathrm{~S}$ dan $113^{\circ} 49^{\prime} 21.0252^{\prime \prime} \mathrm{E}$ 
P-ISSN $2580-7781$

E-ISSN 2615 - 3238

Stasiun $3=7^{\circ} 41^{\prime} 07.3212^{\prime \prime S}$ dan $113^{\circ} 49^{\prime} 37.3512^{\prime \prime} \mathrm{E}$

Stasiun $4=7^{\circ} 41^{\prime} 12.2928^{\prime \prime S}$ dan $113^{\circ} 49^{\prime} 43.8888^{\prime \prime} \mathrm{E}$

Stasiun $5=7^{\circ} 41^{\prime} 05.6^{\prime \prime} \mathrm{S}$ dan $113^{\circ} 49^{\prime} 57.7^{\prime \prime} \mathrm{E}$

Stasiun $6=7^{\circ} 40^{\prime} 59.9592 " \mathrm{~S}$ dan $113^{\circ} 49^{\prime} 53.5152^{\prime \prime} \mathrm{E}$

Data hasil penelitian ditampilkan pada Tabel 2.

Tabel 2. Data Hasil Penelitian

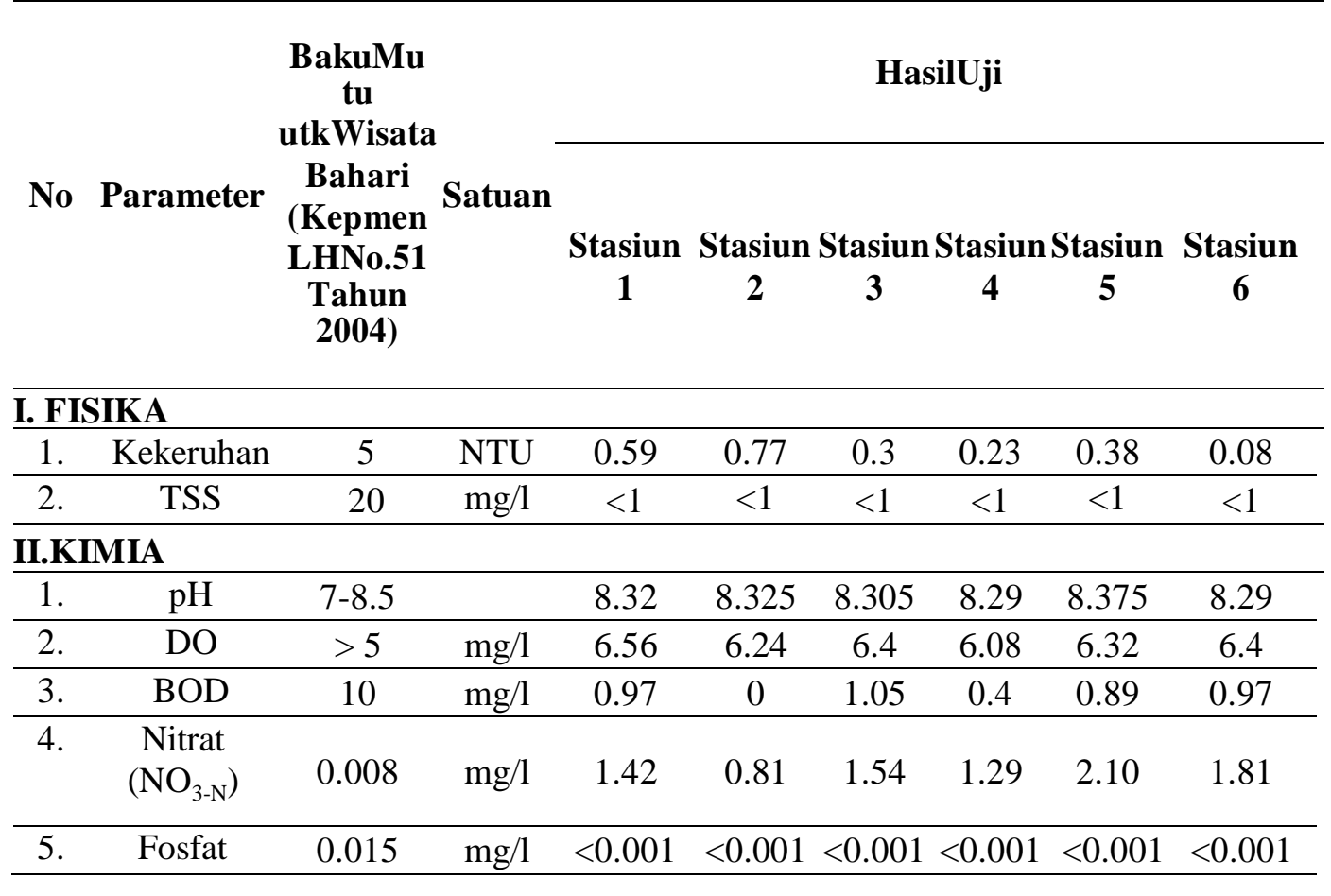

Tabel 2 menampilkan hasil data penelitian masing-masing parameter uji kualitas air pada 6 stasiun sampling baik yang diukur langsung di lapangan maupun hasil yang diperoleh dari Laboratorium. Parameter fisika yang diukur yaitu kekeruhan dan TSS (Total Suspended Solid). Perbandingan data hasil pengukuran parameter kekeruhan dan TSS dengan baku mutu untuk wisata bahari menunjukkan bahwa kekeruhan dan TSS berada pada batas aman yang berarti nilainya tidak melebihi nilai standar baku mutu yang ditetapkan. Hal ini berlaku di enam stasiun pengambilan sampel. Nilai tertinggi kekeruhan berdasarkan pengukuran lapangan adalah 0.77 NTU di stasiun 2 dan nilai terendah pada stasiun 6 dengan nilai 0.08 NTU. Standar baku mutu yang ditetapkan untuk 
P-ISSN $2580-7781$

E-ISSN 2615 - 3238

kekeruhan adalah 5 NTU sehingga nilai tertinggi hasil pengukuran lapangan untuk kecerahan tidak melebihi nilai baku mutu yang telah ditetapkan. Untuk parameter TSS, pengukuran lapangan di enam stasiun menunjukkan nilai kurang dari $1 \mathrm{mg} / \mathrm{l}$, sedangkan nilai ambang batasnya adalah $20 \mathrm{mg} / \mathrm{l}$ sehingga nilai TSS lebih rendah dari nilai ambang batas yang ditetapkan. Kecerahan dan TSS berpengaruh pada penetrasi cahaya ke dalam perairan. Cahaya matahari merupakan syarat untuk terjadinya proses fotosintesis yang dilakukan oleh organisme-organisme yang hidup di dalam air. Dengan fotosintesis organisme mampu melangsungkan kehidupan di dalam air. Selain itu, cahaya juga berpengaruh pada tipe dan distribusi biota dalam air serta suhu perairan.

Parameter kimia kualitas air yang diuji meliputi pH, DO, BOD, nitrat, dan fosfat. Nilai pengujian $\mathrm{pH}, \mathrm{DO}, \mathrm{BOD}$, dan fosfat berada pada rentang nilai yang diijinkan oleh standar baku mutu, kecuali nitrat yang melebihi nilai ambang batas baku mutu yang telah ditetapkan.Keberadaan ion hidrogen menggambarkan nilai pH. Jika $\mathrm{pH}<5$, alkalitas mencapai nol dan larutan bersifat asam sehingga menjadi korosif. $\mathrm{pH}$ berpengaruh pada proses-kimiawi perairan misalnya proses nitrifikasi akan berakhir jika $\mathrm{pH}$ rendah. Rentang nilai $\mathrm{pH}$ yang ditetapkan antara 7 hingga 8.5, sedangkan nilai $\mathrm{pH}$ pengukuran tertinggi sebesar 8.375 pada Stasiun 5 dan terendah 8.29 pada Stasiun 6 dan Stasiun 4, sehingga nilai pH tidak ada yang melebihi nilai standar yang ditetapkan. Nilai standar baku mutu untuk DO adalah diatas $5 \mathrm{mg} / \mathrm{l}$, nilai pengukuran DO di enam stasiun menunjukkan nilai diatas 6 dengan nilai tertinggi $6.56 \mathrm{mg} / \mathrm{l}$ di stasiun 1, sehingga nilai DO di semua stasiun sesuai dengan baku mutu yang ditetapkan. Nilai BOD yang baik, tidak melebihi $10 \mathrm{mg} / \mathrm{l}$ sehingga dari semua stasiun, nilai BOD hasil pengukuran tertinggi sebesar $1.05 \mathrm{mg} / \mathrm{l}$ di stasiun 3, sehingga nilai BOD masih sesuai baku mutu untuk wisata bahari. Nilai fosfat berdasarkan standar baku mutu adalah tidak lebih dari $0.015 \mathrm{mg} / \mathrm{l}$ dan nilai pengukuran fosfat di semua stasiun adalah kurang dari 0.001 , sehingga nilai fosfat memenuhi baku mutu untuk wisata bahari. Hasil berbeda ditunjukkan oleh nilai kandungan nitrat hasil pengukuran di lapangan. Nilai baku mutu untuk nitrat adalah sebesar $0.008 \mathrm{mg} / \mathrm{l}$, tetapi dienam stasiun sampling menunjukkan nilai nitrat lebih dari nilai baku mutu yaitu dengan nilai 
P-ISSN $2580-7781$

E-ISSN 2615 - 3238

tertinggi sebesar $2.1 \mathrm{mg} / \mathrm{l}$ di stasiun 5 . Hal ini menunjukkan kandungan nitrat telah melampaui nilai ambang batas yang ditetapkan oleh pemerintah. Menurut Chu dalam Wardoyo dalam Patty (2015:47), jika kandungan nitrat lebih besar dari $3.5 \mathrm{mg} / \mathrm{l}$ maka dapat membahayakan perairan karena meningkatkan pertumbuhan organisme dengan pesat. Apabila kandungan nitrat 0.9 - $3.5 \mathrm{mg} / \mathrm{l}$ optimum untuk pertumbuhan organisme. Nitrat merupakan sumber utama nitrogen perairan bersama dengan amonium. Menurut Effendi (2003:155) tingkat kesuburan perairan dapat dikelompokkan berdasarkan kadar nitrat yang terkandung di perairan tersebut. Kadar nitrat antara 1-5 mg/l dikelompokkan dalam perairan mesotrofik.

Untuk menentukan status mutu perairan, data hasil penelitian dihitung dengan menggunakan metode Indeks Pencemaran. Tabel 3 hingga Tabel 8 menunjukkan nilai indeks pencemaran stasiun 1 hingga stasiun 6. Nilai indeks pencemaran untuk stasiun 1 diberikan pada Tabel 3. Nilai Indeks Pencemaran stasiun 1 sebesar 8.815 yang berarti status mutu air di stasiun 1 tercemar sedang.

Tabel 3. Nilai Indeks Pencemaran Stasiun 1

\begin{tabular}{lccccc}
\hline \multicolumn{1}{c}{ Parameter } & $\mathbf{C i}$ & $\mathbf{L i j}$ & $\mathbf{C i} / \mathbf{L i j}$ & Cibaru & Ci/LijBaru \\
\hline Kekeruhan & 0.59 & 5 & 0.118 & & 0.118 \\
\hline TSS & $<1$ & 20 & 0.045 & & 0.045 \\
\hline $\mathrm{pH}$ & 8.32 & $7-8.5$ & 3.2 & & 3.526 \\
\hline DO & 6.56 & $>5$ & 0.0733 & 0.44 & 0.073 \\
\hline BOD & 0.97 & 10 & 0.097 & 0.097 \\
\hline Nitrat $\left(\mathrm{NO}_{3-\mathrm{N}}\right)$ & 1.42 & 0.008 & 177.5 & 12.25 \\
\hline Fosfat & $<0.001$ & 0.015 & 0.06 & 0.06 \\
\hline Ci/Lijmaks & & & & 2.25 \\
\hline Ci/Lijrerata & & & \multicolumn{2}{c}{8.815} \\
\hline Pij & & & \multicolumn{2}{c}{} \\
\hline
\end{tabular}

Nilai indeks pencemaran untuk stasiun 2 diberikan pada Tabel 4. Nilai Indeks Pencemaran stasiun 2 sebesar 7.943 artinya status mutu air di stasiun 2 tercemar sedang.

Tabel 4. Nilai Indeks Pencemaran Stasiun 2

\begin{tabular}{lccccc}
\hline Parameter & $\mathbf{C i}$ & $\mathbf{L i j}$ & $\mathbf{C i} / \mathbf{L i j}$ & Cibaru & Ci/LijBaru \\
\hline Kekeruhan & 0.77 & 5 & 0.154 & & 0.154 \\
\hline TSS & $<1$ & 20 & 0.045 & & 0.045 \\
\hline pH & 8.325 & $7-8.5$ & 3.3 & & 3.593 \\
\hline DO & 6.24 & $>5$ & 0.127 & 0.76 & 0.127 \\
\hline
\end{tabular}


P-ISSN 2580 - 7781

E-ISSN 2615 - 3238

\begin{tabular}{lcccc}
\hline BOD & 0 & 10 & 0 & 0 \\
\hline Nitrat $\left(\mathrm{NO}_{3-\mathrm{N}}\right)$ & 0.81 & 0.008 & 101.25 & 11.027 \\
\hline Fosfat & $<0.001$ & 0.015 & 0.06 & 0.06 \\
\hline Ci/Lijmaks & & \multicolumn{2}{c}{2.11 .027} \\
\hline Ci/Lijrerata & \multicolumn{3}{c}{7.943} \\
\hline Pij & \multicolumn{3}{c}{ Nilai indeks pencemaran untuk stasiun 3 diberikan pada Tabel 5. Nilai Indeks }
\end{tabular}

Pencemaran stasiun 3 sebesar 8.932 artinya status mutu air di stasiun 3 tercemar sedang.

Tabel 5. Nilai Indeks Pencemaran Stasiun 3

\begin{tabular}{|c|c|c|c|c|c|}
\hline Parameter & $\mathbf{C i}$ & Lij & $\mathrm{Ci} / \mathrm{Lij}$ & Cibaru & Ci/LijBaru \\
\hline Kekeruhan & 0.3 & 5 & 0.06 & & 0.06 \\
\hline TSS & $<1$ & 20 & 0.045 & & 0.045 \\
\hline $\mathrm{pH}$ & 8.305 & $7-8.5$ & 2.8 & & 3.236 \\
\hline DO & 6.4 & $>5$ & 0.100 & 0.6 & 0.1 \\
\hline BOD & 1.05 & 10 & 0.105 & & 0.105 \\
\hline $\operatorname{Nitrat}\left(\mathrm{NO}_{3-\mathrm{N}}\right)$ & 1.54 & 0.008 & 192.5 & & 12.422 \\
\hline Fosfat & $<0.001$ & 0.015 & 0.06 & & 0.06 \\
\hline Ci/Lijmaks & & & & & 12.422 \\
\hline Ci/Lijrerata & & & & & 2.29 \\
\hline $\mathrm{Pij}$ & & & & & 8.932 \\
\hline
\end{tabular}

Nilai indeks pencemaran untuk stasiun 4 diberikan pada Tabel 6. Nilai Indeks Pencemaran stasiun 4 sebesar 8.656 artinya status mutu air di stasiun 4 tercemar sedang.

Tabel 6. Nilai Indeks Pencemaran Stasiun 4

\begin{tabular}{lccccc}
\hline \multicolumn{1}{c}{ Parameter } & $\mathbf{C i}$ & $\mathbf{L i j}$ & $\mathbf{C i} / \mathbf{L i j}$ & Cibaru & Ci/LijBaru \\
\hline Kekeruhan & 0.23 & 5 & 0.046 & & 0.046 \\
\hline $\mathrm{TSS}$ & $<1$ & 20 & 0.045 & 0.045 \\
\hline $\mathrm{pH}$ & 8.29 & $7-8.5$ & 2.6 & 3.07 \\
\hline $\mathrm{DO}$ & 6.08 & $>5$ & 0.153 & 0.92 & 0.153 \\
\hline $\mathrm{BOD}$ & 0.4 & 10 & 0.04 & 0.04 \\
\hline Nitrat $\left(\mathrm{NO}_{3-\mathrm{N}}\right)$ & 1.29 & 0.008 & 161.25 & 12.04 \\
\hline Fosfat & $<0.001$ & 0.015 & 0.06 & 0.06 \\
\hline Ci/Lijmaks & & & & 12.04 \\
\hline Ci/Lijrerata & & & 2.21 \\
\hline Pij & & & 8.656 \\
\hline
\end{tabular}


P-ISSN $2580-7781$

E-ISSN 2615 - 3238

Nilai indeks pencemaran untuk stasiun 5 diberikan pada Tabel 7. Nilai Indeks Pencemaran stasiun 5 sebesar 9.432 artinya status mutu air di stasiun 5 tercemar sedang.

Tabel 7. Nilai Indeks Pencemaran Stasiun 5

\begin{tabular}{lccccc}
\hline \multicolumn{1}{c}{ Parameter } & $\mathbf{C i}$ & $\mathbf{L i j}$ & $\mathbf{C i} / \mathbf{L i j}$ & Cibaru & Ci/LijBaru \\
\hline Kekeruhan & 0.38 & 5 & 0.076 & & 0.076 \\
\hline $\mathrm{TSS}$ & $<1$ & 20 & 0.045 & & 0.045 \\
\hline $\mathrm{pH}$ & 8.375 & $7-8.5$ & 5.0 & & 4.49 \\
\hline $\mathrm{DO}$ & 6.32 & $>5$ & 0.113 & 0.68 & 0.113 \\
\hline BOD & 0.89 & 10 & 0.089 & & 0.089 \\
\hline Nitrat $\left(\mathrm{NO}_{3-\mathrm{N}}\right)$ & 2.1 & 0.008 & 262.5 & 13.09 \\
\hline Fosfat & $<0.001$ & 0.015 & 0.06 & 0.06 \\
\hline Ci/Lijmaks & & & & 13.09 \\
\hline Ci/Lijrerata & & & & 2.567 \\
\hline Pij & & & 9.432 \\
\hline
\end{tabular}

Nilai indeks pencemaran untuk stasiun 6 diberikan pada Tabel 8. Nilai Indeks Pencemaran stasiun 6 sebesar 9.178 artinya status mutu air di stasiun 6 tercemar sedang.

Tabel 8. Nilai Indeks Pencemaran Stasiun 6

\begin{tabular}{lccccc}
\hline Parameter & $\mathbf{C i}$ & $\mathbf{L i j}$ & $\mathbf{C i} / \mathbf{L i j}$ & Cibaru & Ci/LijBaru \\
\hline Kekeruhan & 0.08 & 5 & 0.016 & & 0.016 \\
\hline $\mathrm{TSS}$ & $<1$ & 20 & 0.045 & & 0.045 \\
\hline $\mathrm{pH}$ & 8.29 & $7-8.5$ & 2.6 & & 3.05 \\
\hline $\mathrm{DO}$ & 6.4 & $>5$ & 0.100 & 0.6 & 0.100 \\
\hline BOD & 0.97 & 10 & 0.097 & & 0.097 \\
\hline Nitrat$\left(\mathrm{NO}_{3-\mathrm{N}}\right)$ & 1.81 & 0.008 & 226.25 & 0.06 \\
\hline Fosfat & $<0.001$ & 0.015 & 0.06 & 12.773 \\
\hline Ci/Lijmaks & & & & 2.306 \\
\hline Ci/Lijrerata & & & & 9.178 \\
\hline Pij & & & & \\
\hline
\end{tabular}

\section{KESIMPULAN}

Perbandingan tujuh parameter kualitas air dengan baku mutu kualitas air untuk wisata bahari berdasarkan Kepmen LH No. 51 Tahun 2004 menunjukkan bahwa parameter kekeruhan, TSS, pH, DO, BOD, dan fosfat menunjukkan kriteria aman yang nilainya sesuai dan atau tidak melebihi nilai baku mutu yang 
P-ISSN $2580-7781$

E-ISSN 2615 - 3238

ditetapkan. Nilai nitrat melebihi nilai baku mutu kualitas air untuk wisata bahari berdasarkan Kepmen LH No. 51 Tahun 2004.

Berdasarkan hubungan tingkat ketercemaran dengan kriteria Indeks Pencemaran dapat diketahui bahwa status mutu air Stasiun 1 hingga Stasiun 6 tercemar sedang karena nilai Indeks Pencemaran berkisar 5,0 $\leq \operatorname{PIj} \leq 10$.

\section{DAFTAR PUSTAKA}

Effendi H. Telaah Kualitas Air. Yogyakarta: PT Kanisius, 2003

Hamuna, Baigo., Tanjung, Rosye H.R., Suwito, Maury, Hendra K., Alianto. (2018). Kajian kualitas air laut dan indeks pencemaran berdasarkan parameter fisika-kimia di Perairan Distrik Depapre Jayapura. Jurnal Ilmu Lingkungan, 16(1), 35-43.

Hariyadi S dan Effendi H. (2016). Penentuan Status Kualitas Perairan Pesisir. Bahan Perkuliahan. Bogor: IPB.

Kementerian Negara Lingkungan Hidup. (2004). Keputusan Menteri Lingkungan Hidup Nomor 51 Tahun 2004 Tentang Baku Mutu Air Laut.

Kementerian Negara Lingkungan Hidup. (2003). Keputusan Menteri Lingkungan Hidup Nomor 115 Tahun 2003 Tentang Pedoman Penentuan Status Mutu Air.

Matahelumual, B.C. (2007). Penentuan Status Mutu Air dengan Sistem STORET di Kecamatan Bantar Gebang. Jurnal Geologi Indonesia,2(2), 113-118.

Mishra, P., Panda, U.S., Pradhan, U., Kumar, C.S., Naik, S., Begum, M., Ishwarya, J. (2015). Coastal Water Quality Monitoring and Modelling off Chennai City. Procedia Engineering, 116, 955-962.

P Anrosana, I. A., Gemaputri, A. A.(2017). Kajian Daya Dukung (Carrying capacity) Lingkungan Perairan Pantai Pasir Putih Situbondo bagi Pengembangan Usaha Keramba Jaring Apung, Jurnal Ilmiah INOVASI, 17(2),73-79.

Patty, S.I., Arfah, Hairati, Abdul M.S. (2015). Zar hara (fosfat, nitrat), oksigen terlarut dan pH kaitannya dengan kesuburan di perairan jikumerasa, pulau buru. Jurnal Pesisir dan Laut Tropis, 1(1),43-50.

Pemerintah Republik Indonesia. (1990). Peraturan Pemerintah Republik Indonesia Nomor 20 Tahun 1990 Tentang Pengendalian Pencemaran Air.

Pemerintah Kabupaten Situbondo. (2012). Peraturan Bupati Situbondo Nomor 19 Tahun 2012 Tentang Pencadangan Kawasan Terumbu Karang 
P-ISSN $2580-7781$

E-ISSN 2615 - 3238

Pasir Putih sebagai Kawasan Konservasi Perairan Daerah Kabupaten Situbondo.

Subagio, I. B., Aunurohim. (2013). Struktur Komunitas Spons Laut (Porifera) di Pantai Pasir Putih, Situbondo, Jurnal Sains dan Seni POMITS, 2 (2), E-159 - E-165.

Sukandar, Harsindhi CJ, Dewi CSU, Handayani M, Maulana AW, Supriyadi, Bahroni A. (2016). Profil Desa Pesisir Provinsi Jawa Timur Volume 1 (Utara Jawa Timur). Surabaya: Bidang Kelautan, Pesisir, dan Pengawasan Dinas Perikanan dan Kelautan Provinsi Jawa Timur.

Google Earth. (2020). Situbondo Maps. 